\title{
Immature hemodialysis arteriovenous fistulas: What should we aim for?
}

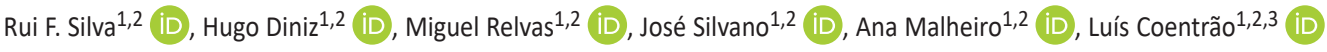 \\ ${ }^{1}$ Nephrology Department, Centro Hospitalar e Universitário de São João, Porto, Portugal \\ ${ }^{2}$ Nephrology \& Infectious Diseases R\&D, i3S - Instituto de Investigação e Inovação em Saúde da Universidade do Porto, Porto, Portugal \\ ${ }^{3}$ Faculty of Medicine, University of Porto, Porto, Portugal
}

\section{ABSTRACT}

Arteriovenous fistulas (AVFs) are the first-choice vascular access for most HD patients. Up to $60 \%$ of AVFs do not mature adequately, mostly due to stenosis. Surgical and endovascular techniques can rescue up to $80 \%$ of these AVFs from primary failure, allowing them to be safely and effectively used in HD, preserving venous capital, and avoiding placement of CVCs and associated complications. This article reviews and summarizes the existing literature, offering a practical approach on early identification, treatment, and monitoring of immature AVFs.

Key words: arteriovenous fistula, hemodialysis, angioplasty.

C 2021 Portuguese Journal of Nephrology \& Hypertension. Published by Publicações Ciência \& Vida This is an open access article under the CC BY-NC-ND license (http://creativecommons.org/licenses/by-nc-nd/4.0/).

\section{INTRODUCTION}

Vascular access in hemodialysis (HD) is a sine qua non to treat patients, representing a lifeline. There are three main types of vascular access in hemodialysis - arteriovenous fistulas (AVFs), arteriovenous grafts (AVGs), and central venous catheters (CVCs). Compared to AVGs and CVCs, AVFs have lower complication and reintervention rates and longer cumulative patency. In addition, patients with AVFs have lower access-related hospitalization and mortality rates ${ }^{1-3}$. For these reasons, AVFs are deemed as the first-choice access for most patients who have suitable vessels and a long life-expectancy ${ }^{4}$. However, decisions regarding vascular access creation should always take into consideration the patient's overall End Stage Kidney Disease (ESKD) Life-Plan, which is a personalized strategy for living with ESKD, encompassing vascular access planning, ideally made together and periodically reviewed by the patient and a coordinated chronic kidney disease (CKD) management team. Attainment of the "right access, in the right patient, at the right time, for the right reasons" contrasts with "fistula first" policies as a more patient-centered approach to care $\mathrm{c}^{4,5}$.

AVFs result from an anastomosis between an artery and a vein, which can be created by open surgery or, more recently, percutaneous endovascular techniques. Once created, the arterialized vein goes through a maturation process where it acquires the necessary diameter and flow to be cannulated repeatedly, safely, providing an adequate HD treatment. Provided that all goes well, this process usually lasts 4 to 6 weeks ${ }^{6}$. However, 20 to $60 \%$ of newly created AVFs do not mature adequately to be used in $\mathrm{HD}$ - primary failure rate or non-maturation rate ${ }^{7-10}$. This largely relates to stenoses adjacent to the anastomosis or in the outflow tract and can be corrected by open surgical or percutaneous endovascular rescue techniques if identified in time ${ }^{11}$. Furthermore, excluding AVFs with primary failure, only $70 \%$ of AVFs are patent after one year without being submitted to an intervention to assist patency - primary patency or unassisted primary patency rate?

This article reviews and summarizes the existing literature, including recent guidelines, on early identification, treatment, and follow-up of immature AVFs, offering a practical approach to reducing primary failure rates, thrombosis, and to improving their overall longevity.

\section{AVF MATURATION}

Once an AVF is created, there is a reduction in vascular resistance which generates increased blood flow. The increased flow in turn results in augmented wall shear and circumferential stress, the hemodynamic forces driving both artery and vein remodeling. The endpoint of this process is referred to as AVF maturation, which can be characterized physiologically using criteria related to blood flow and vessel diameter ${ }^{12}$ (Table I). Almost fifty percent of the AVF total flow increase was found to take place on the first day after the procedure ${ }^{13}$ and full maturation in uneventful new AVFs is usually accomplished between the second and fourth week ${ }^{14}$ - as such, cannulation is preferable after the fourth week $^{15}$. However, if it will avoid placement of a central venous catheter, cannulation might be performed after the second week ${ }^{15,16}$ without increasing the risk of AVF failure, according to an analysis from the DOPPS ${ }^{17}$. From the same study, only AVFs cannulated within 14 days were at increased risk of subsequent failure $(2.1-\text { fold })^{17}$.

Physical examination by experienced staff may predict maturation in up to $80 \%$ of $A V F s{ }^{14,18}$. Equally, physical examination has great accuracy detecting underlying culprit lesions for non-maturation, such 


\section{Table I}

AVF maturation criteria ${ }^{14,16,19,20}$

\begin{tabular}{|c|c|}
\hline Blood flow & $\geq 500$ to $600 \mathrm{~mL} / \mathrm{min}$ \\
\hline Diameter & $\geq 4$ to $6 \mathrm{~mm}$ \\
\hline Depth & $\leq 6 \mathrm{~mm}$ \\
\hline Cannulation length & $\geq 6 \mathrm{~cm}$ \\
\hline Physical examination & $\begin{array}{l}\text { Systolic and diastolic thrill, soft and compressible pulse, low } \\
\text { rumbling pitch with a prominent diastolic component bruit, } \\
\text { accessible to cannulation }\end{array}$ \\
\hline
\end{tabular}

as inflow or outflow stenosis ${ }^{19}$. Nonetheless, there is significant variability between dialysis staff and centers justifying the usual added use of objective and reproducible physical parameters (blood flow, vein diameter and depth) obtained by Doppler ultrasound, which is an accurate, noninvasive, inexpensive and diagnostic test (Table I). A 2002 University of Alabama study proposed a combination of blood flow $\geq 500 \mathrm{~mL} / \mathrm{min}$ and vein diameter $\geq 4 \mathrm{~mm}$ for AVF maturation criteria, generally present after a month, which has a positive predictive value of $95 \%$ for adequate AVF utilization and, hence, maturation ${ }^{14}$ (Table I). Subsequently, in 2006, the Kidney Diseases Outcomes Quality Initiative (KDOQI) clinical practice guideline proposed, based on expert opinions, a combination of blood flow $\geq 600 \mathrm{ml} / \mathrm{min}$, vein diameter $\geq 6 \mathrm{~mm}$ and depth from the skin $\leq 6 \mathrm{~mm}$ - "rule of $6^{\prime \prime 20}$ (Table I). More recently, in a study of CKD patients undergoing AVF creation, blood flow, vein diameter, and depth obtained by Doppler ultrasound, moderately predicted the likelihood of AVF maturation at six weeks ${ }^{21}$.

Primary failure rates due to non-maturation has increased over the years, which is probably a result of demographic changes in hemodialysis patients from young to elderly, comorbid patients with cardiovascular disease, and diabetes mellitus as a major cause for renal failure ${ }^{7}$. This shift translates into calcified, noncompliant arteries, and sclerotic veins, resulting in inappropriate vascular remodeling, intimal hyperplasia, and failure to mature ${ }^{22}$. However, nearly all immature AVFs have a treatable underlying lesion, mostly stenosis, that can generally be identified and salvaged by surgical or endovascular techniques ${ }^{23-25}$. According to one study, $80 \%$ of these AVFs could be rescued, thereby producing an increase in the likelihood of maturation by approximately $50 \%$ comparing to immature AVFs not submitted to these treatments ${ }^{25}$.
For these reasons, new AVFs maturation criteria should be assessed by physical and Doppler ultrasound examination 4 to 6 weeks after their creation, to identify immature AVFs' underlying problems and consequently program elective treatment ${ }^{15,16,26}$. According to our review of the literature, we propose a synthesized approach algorithm for newly created AVFs (see Figure 1). There are two degrees of AVF immaturity - physiological and/or clinical. An AVF is considered physiologically immature if it has low blood flow and/or a small vessel diameter, as measured by Doppler ultrasound. This is generally related to stenotic phenomena, which can be perceived by physical examination and/or Doppler ultrasound (Table II). Additionally, and despite physiological maturity, an AVF can only be considered fully mature if it is clinically accessible for safe, repeated cannulation, according to depth, location on patient's arm, and/or length. Deep (e.g. arm brachiobasilic AVF or obese patients) or posterior AVFs (e.g. forearm ulnar-basilic AVF) should be considered for surgical superficialization or transposition, whilst AVF stenosis compromising physiological maturity is an indication for surgical or endovascular treatment, depending on its location and available local resources $4,15,16$.

\section{IMMATURE AVFS RESCUE TECHNIQUES}

There are no randomized clinical trials comparing surgical to endovascular techniques on the rescue of immature AVFs. Stenoses located on the afferent artery or on a vein segment other than the juxta-anastomotic region are usually treated endovascularly by percutaneous transluminal angioplasty (PTA), given its minimally invasive nature and safety ${ }^{11,16}$. Outcomes with PTA on afferent artery stenosis look particularly favorable, comparing to other locations (Table III) ${ }^{27}$. As for juxta-anastomotic venous stenosis ( $\leq$ $5 \mathrm{~cm}$ from anastomosis), a narrative review of 28 non-randomized studies suggests a better primary patency rate with surgical revision, particularly with proximal neoanastomosis (PNA) ${ }^{11}$ (Table III). A retrospective study comparing PNA to PTA in immature radialcephalic AVFs juxta-anastomotic stenosis showed a better primary patency rate with the former (71\% vs $41 \%)$, despite similar complication and secondary patency rates ${ }^{28}$. This data could point to surgical revision as the first line option for immature AVFs with juxta-anastomotic stenosis ${ }^{16}$ - however, due to the lack of randomized clinical trials, this is still not consensual. According to

\section{Table II}

AVF stenosis criteria (considering immature AVFs) 16,19

\begin{tabular}{|c|c|c|}
\hline Stenosis location & Physical examination & Doppler ultrasound \\
\hline $\begin{array}{l}\text { Inflow (arterial or venous } \\
\text { juxta-anastomotic) }\end{array}$ & $\begin{array}{l}\text { - Flat on inspection after stenosis } \\
\text { - Absent or weak thrill/pulse after stenosis (increased juxta-anastomotic } \\
\text { pulse between artery and juxta-anastomotic stenosis) } \\
\text { - Negative pulse augmentation test } \\
\text { - Excessive collapse on arm elevation test }\end{array}$ & $\begin{array}{l}\text { - Failure to attain a Qa } \geq 500 \mathrm{~mL} / \mathrm{min} \\
\text { and } \\
\text { - Reduction }>50 \% \text { of the vessel lumen (morphological criteria) } \\
\text { and (at least one functional criteria) }\end{array}$ \\
\hline Outflow (venous) & $\begin{array}{l}\text { - Engorged on inspection between artery and venous stenosis } \\
\text { - Systolic thrill (loss of diastolic component) } \\
\text { - Strong water-hammer pulse between artery and venous stenosis } \\
\text { - Absent drainage on arm elevation test }\end{array}$ & $\begin{array}{l}\text { - Ratio }>2 \text { of the PSV between the stenosis area and the pre-stenotic area } \\
\text { or } \\
\text { - PSV }>400 \mathrm{~cm} / \mathrm{s} \text { in a non-anastomosis zone }\end{array}$ \\
\hline
\end{tabular}

PSV - peak systolic velocity; Qa - blood flow 


\section{Figure 1}

Approach algorithm to recently created AVFs.

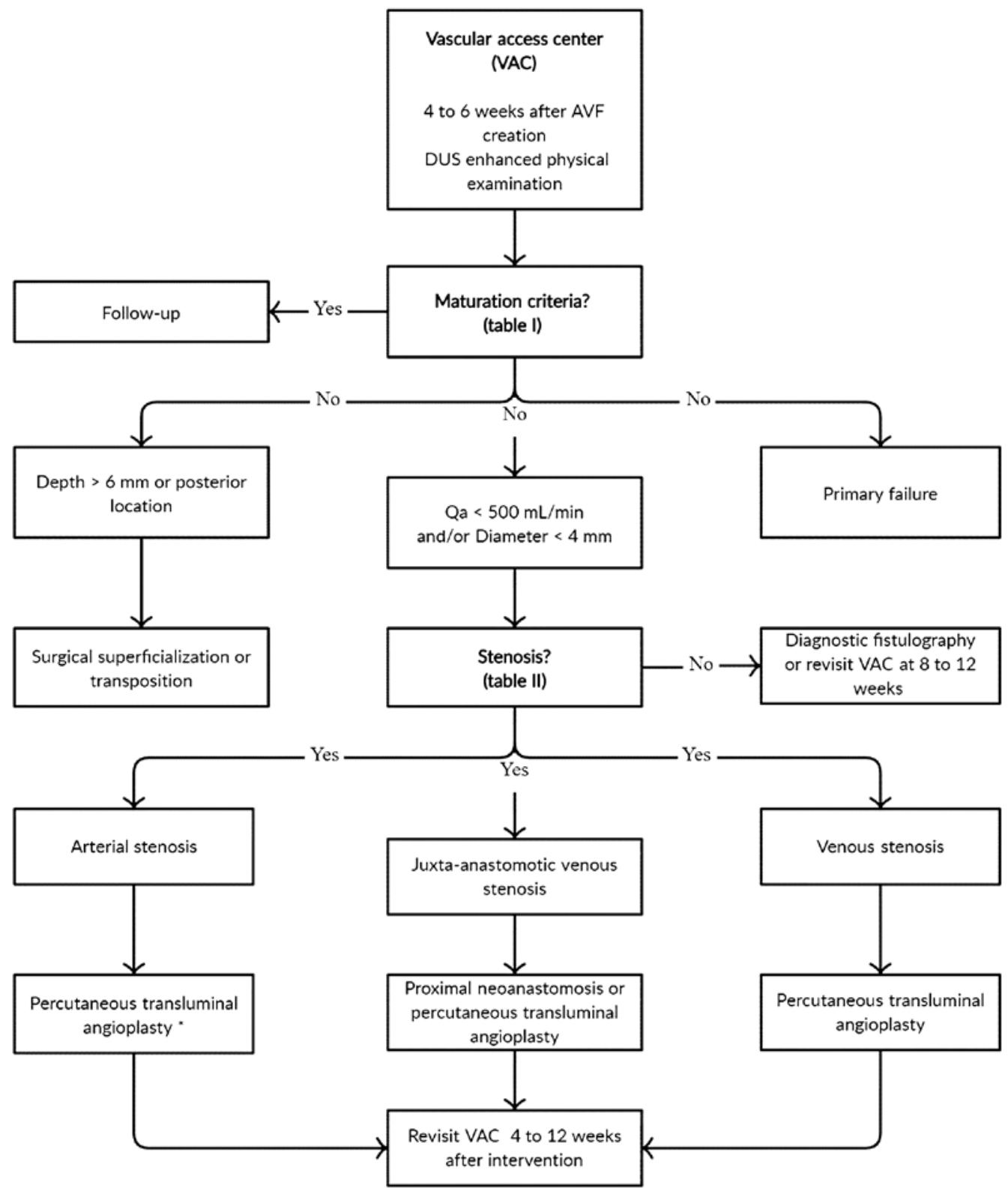

AVF - arteriovenous fistula; DUS - doppler ultrasound; Qa - blood flow. Primary failure - deemed surgically or endovascularly unsalvageable by the vascular access center team). * Assuming no risk of provoking steal syndrome (hand hypoperfusion).

the 2019 guidelines from the European Renal Best Practice and KDOQI, there's insufficient evidence to support one over the oth$\mathrm{er}^{4,15}$ (Table IV).

Meanwhile, the role of surgical or endovascular exclusion of accessory veins when rescuing immature AVFs remains to be elucidated, since these almost always coexist with stenosis, which should be treated first $^{11,29}$. However, if this is not the case and manual compression of the accessory vein translates into enhanced blood flow through the AVF, it could be worthwhile to ligate surgically or endovascularly ${ }^{30}$. On the same note, there is currently insufficient data to recommend intraoperative maturation enhancement techniques (type of anesthesia, surgical technique, suture technique, anastomotic devices, intra-operatory angioplasty followed by balloon-assisted maturation), early $(<6$ weeks) protocol-driven sequential balloon-assisted maturation or pharmacological interventions to improve AVF maturation rates ${ }^{4}$. 
Table III

Endovascular (PTA) and surgical (PNA) reported outcomes ${ }^{15}$

\begin{tabular}{l|c|c|c|c|c}
\multicolumn{1}{c|}{ Technique } & N studies & N patients & Success rate & $\begin{array}{c}\text { 1-year primary } \\
\text { patency rate }\end{array}$ & $\begin{array}{c}\text { 1-year secondary } \\
\text { patency rate }\end{array}$ \\
\hline PTA - venous juxta-anastomotic stenosis/venous stenosis & 14 & 657 & $43-97 \%$ & $28-72 \%$ & $68-97 \%$ \\
PTA - afferent artery & 2 & 99 & $91-98 \%$ & $65-83 \%$ & $86-96 \%$ \\
PNA - venous juxta-anastomotic & 2 & 71 & $90 \%$ & $71-78 \%$ & $87-95 \%$
\end{tabular}

PTA - percutaneous transluminal angioplasty; PNA - proximal neoanastomosis

\section{$\underline{\text { Table IV }}$}

Clinical guidelines and recommendations on AVF maturation procedures 4,15,26,16

\section{KDOQI 2019 | "KDOQI Clinical Practice Guideline For Vascular Access: 2019 update"}

- There is inadequate evidence for $\mathrm{KDOQ}$ to make a recommendation on the preferred use of surgical or endovascular techniques for postoperative maturation. It is reasonable to consider a careful individualized approach to using either surgical techniques or endovascular techniques when needing to intervene on an AV access to enhance maturation postoperatively.

European Renal Best Practice 2019 | "Clinical practice guideline on peri- and postoperative care of arteriovenous fistulas and grafts for haemodialysis in adults"

- We suggest there is insufficient evidence to support open surgical over endovascular interventions as the preferred treatment for non-maturing arteriovenous fistulas in adults with end-stage kidney disease. (2D)

Advice for clinical practice:

- Decisions on how to treat non-maturing arteriovenous fistulas are likely best based on local resources, experience and success rates.

- Institutions likely benefit from building a dedicated multidisciplinary vascular access team, with clinical experience in various techniques available for non-maturing arteriovenous fistulas.

European Society for Vascular Surgery 2018 | "Vascular Access: 2018 Clinical Practice Guidelines of the European Society for Vascular Surgery"

- If an arteriovenous fistula fails to mature by 6 weeks, additional investigations (like duplex ultrasound) should be considered in order to achieve prompt diagnosis and treatment (2C). Grupo Español Multidisciplinar del Acceso Vascular 2017 | "Spanish Clinical Guidelines on Vascular Access for Haemodialysis"

- We recommend a clinical check-up be performed at 4-6 weeks to definitively detect delay or absence of arteriovenous fistula maturation from its creation to this moment and elective treatment be proposed. We recommend confirming the suspected lack of maturation by Doppler Ultrasound.

- We suggest early treatment of the non-matured native arteriovenous fistula to favour maturation and to prevent thrombosis and definitive loss

- We recommend percutaneous or surgical techniques not be used systematically to promote maturation of native arteriovenous fistulae

- We suggest surgery as the first treatment option (proximal reanastomosis) in native arteriovenous fistulae with maturation failure associated with juxta-anastomotic stenosis. In cases where this is not possible, endovascular treatment (percutaneous angioplasty) should be proposed

- We suggest significant accessory veins associated with maturation failure be disconnected by percutaneous ligation, surgical ligation or endovascular embolisation with coils. We suggest endovascular treatment be used in the presence of stenosis and surgical treatment when there is no stenosis as the first option, given the lower complexity and healthcare costs

- We recommend angioplasty in cases of non-matured native arteriovenous fistulae with proximal venous stenosis

- We suggest angioplasty of the arterial stenosis when this is the cause of non-maturation of arteriovenous fistula, in cases in which the vascularization of the limb is not compromised

\section{MONITORING AFTER MATURATION}

AVFs submitted to more than one rescue intervention before maturation have a higher risk of thrombosis and permanent loss than AVFs that mature with one or no interventions. Furthermore, in these cases, more interventions are required to maintain long-term patency ${ }^{31,32}$. Follow-up surveillance programs of mature AVFs operate under the assumption that early identification and preemptive treatment of stenosis may prevent thrombosis and permanent access loss. Clinical monitoring through physical examination of the AVF by experienced staff has high sensitivity and specificity for the detection of AVF stenosis ${ }^{19}$. However, given AVF Qa-based surveillance's possible added benefit on the early identification of stenosis, reduction of thrombosis, and permanent access loss ${ }^{33-36}$, periodic assessment by Doppler ultrasound in addition to clinical monitoring could be considered (especially, but not exclusively) on AVFs submitted to rescue interventions before maturation, due to their higher risk of thrombosis and permanent access loss. However, formal evidence-based recommendations for the latter strategy over clinical monitoring alone are lacking due to insufficient data ${ }^{4,15}$.

\section{Multidisciplinary care}

To start and sustain HD with an adequately mature AVF depends on the work of multiple professionals - nephrologists, vascular surgeons, interventionalists, and nurses. In addition to an adequate referral timing for AVF construction, vascular mapping, and surgical experience, a good outcome is best attained by implementing protocolized programs for AVF follow-up, involving multidisciplinary participation ${ }^{16}$. These programs are probably most effective if there is: 1) consensus regarding procedures to identify AVF non-maturation, underlying 
problem, treatment, and follow-up; 2) close ongoing communication among all parties involved; 3 ) a dedicated vascular access coordinator who acts as a liaison between all services; 4) prospective tracking of outcomes with continuous quality assessment and improvement ${ }^{37}$. In Spain, the replacement of an isolated vascular surgery medical appointment by a joint nephrology and vascular surgery appointment with Doppler ultrasound and objective criteria for radial-cephalic AVF creation and AVF elective treatment resulted in an improvement of the primary failure rates ${ }^{38}$.

\section{CONCLUSION}

AVFs are first-choice vascular access for most HD patients. Some AVFs do not mature adequately, mostly due to stenosis. Surgical and endovascular techniques can rescue an important percentage of these AVFs from primary failure, allowing them to be safely and effectively used in HD, preserving venous capital and avoiding the placement of CVCs and associated complications. Hospitals and HD clinics should aim to systematically evaluate AVFs four to six weeks after surgery to facilitate timely diagnosis of AVF non-maturation and subsequent orientation for elective treatment according to the underlying cause. These AVFs should then be periodically assessed for dysfunction to preemptively correct any reoccurring stenoses, ideally through multidisciplinary protocolized follow-up programs.

Disclosure of potential conflicts of interest: none declared

\section{References}

1. Ravani P, Palmer SC, Oliver MJ, Quinn RR, MacRae JM, Tai DJ, et al. Associations between hemodialysis access type and clinical outcomes: a systematic review. J Am Soc Nephrol. 2013; 24: 465-73.

2. Nassar GM and Ayus JC. Infectious complications of the hemodialysis access. Kidney Int. 2001; 60: 1-13.

3. Gruss E, Portolés J, Tato A, Hernández T, López-Sánchez P, Velayos P, et al. [Clinical and economic repercussions of the use of tunneled haemodialysis catheters in a health area]. Nefrologia. 2009; 29: 123-9.

4. Lok CE, Huber TS, Lee T, Shenoy S, Yevzlin AS, Abreo K, et al. KDOQI Clinical Practice Guideline for Vascular Access: 2019 Update. Am J Kidney Dis. 2020; 75: S1-s164.

5. Woo $\mathrm{K}$ and Lok CE. New insights into dialysis vascular access: what is the optimal vascular access type and timing of access creation in ckd and dialysis patients? Clin J Am Soc Nephrol. 2016; 11: 1487-94.

6. Asif A, Roy-Chaudhury P and Beathard GA. Early arteriovenous fistula failure: a logical proposal for when and how to intervene. Clin J Am Soc Nephrol. 2006; 1: 332-9.

7. Al-Jaishi AA, Oliver MJ, Thomas SM, Lok CE, Zhang JC, Garg AX, et al. Patency rates of the arteriovenous fistula for hemodialysis: a systematic review and meta-analysis. Am J Kidney Dis. 2014; 63: 464-78.

8. Wilmink T, Hollingworth L, Powers S, Allen C and Dasgupta I. Natural history of common autologous arteriovenous fistulae: consequences for planning of dialysis access. Eur J Vasc Endovasc Surg. 2016; 51: 134-40.

9. Masengu A, Maxwell AP and Hanko JB. Investigating clinical predictors of arteriovenous fistula functional patency in a European cohort. Clinical Kidney Journal. 2015; 9: $142-7$.

10. Dember LM, Beck GJ, Allon M, Delmez JA, Dixon BS, Greenberg A, et al. Effect of clopidogrel on early failure of arteriovenous fistulas for hemodialysis: a randomized controlled trial. JAMA. 2008; 299: 2164-71.

11. Tordoir JHM, Zonnebeld N, van Loon MM, Gallieni M and Hollenbeck M. Surgical and endovascular intervention for dialysis access maturation failure during and after arteriovenous fistula surgery: review of the evidence. Eur J Vasc Endovasc Surg. 2018; 55: 240-8.

12. Donnelly SM and Marticorena RM. When is a new fistula mature? The emerging science of fistula cannulation. Semin Nephrol. 2012; 32: 564-71.

13. Lomonte C, Casucci F, Antonelli M, Giammaria B, Losurdo N, Marchio G, et al. Is there a place for duplex screening of the brachial artery in the maturation of arteriovenous fistulas? Seminars in Dialysis. 2005; 18: 243-6

14. Robbin ML, Chamberlain NE, Lockhart ME, Gallichio MH, Young CJ, Deierhoi MH, et al. Hemodialysis arteriovenous fistula maturity: US evaluation. Radiology. 2002; 225: 59-64

15. Gallieni M, Hollenbeck M, Inston N, Kumwenda M, Powell S, Tordoir J, et al. Clinical practice guideline on peri- and postoperative care of arteriovenous fistulas and grafts for haemodialysis in adults. Nephrol Dial Transplant. 2019; 34: ii1-ii42.
16. Ibeas J, Roca-Tey R, Vallespín J, Moreno T, Moñux G, Martí-Monrós A, et al. Spanish Clinical Guidelines on Vascular Access for Haemodialysis. Nefrologia. 2017; 37 Suppl 1: 1-191.

17. Rayner HC, Pisoni RL, Gillespie BW, Goodkin DA, Akiba T, Akizawa T, et al. Creation, cannulation and survival of arteriovenous fistulae: data from the Dialysis Outcomes and Practice Patterns Study. Kidney Int. 2003; 63: 323-30.

18. Ferring $\mathrm{M}$, Henderson J and Wilmink $\mathrm{T}$. Accuracy of early postoperative clinical and ultrasound examination of arteriovenous fistulae to predict dialysis use. J Vasc Access. 2014; 15: 291-7.

19. Coentrão L, Faria B and Pestana M. Physical examination of dysfunctional arteriovenous fistulae by non-interventionalists: a skill worth teaching. Nephrology Dialysis Transplantation. 2011; 27: 1993-6.

20. Clinical practice guidelines for vascular access. Am J Kidney Dis. 2006; 48 Suppl 1: S176-247.

21. Robbin ML, Greene T, Allon M, Dember LM, Imrey PB, Cheung AK, et al. Prediction of arteriovenous fistula clinical maturation from postoperative ultrasound measurements: Findings from the Hemodialysis Fistula Maturation Study. J Am Soc Nephrol. 2018; 29: 2735-44.

22. Gameiro J and Ibeas J. Factors affecting arteriovenous fistula dysfunction: a narrative review. J Vasc Access. 2020; 21: 134-47.

23. Nassar GM, Nguyen B, Rhee E and Achkar K. Endovascular treatment of the "failing to mature" arteriovenous fistula. Clin J Am Soc Nephrol. 2006; 1: 275-80.

24. McLafferty RB, Pryor RW, Johnson CM, Ramsey DE and Hodgson KJ. Outcome of a comprehensive follow-up program to enhance maturation of autogenous arteriovenous hemodialysis access. Journal of Vascular Surgery. 2007; 45: 981-5.

25. Singh $\mathrm{P}$, Robbin $\mathrm{ML}$, Lockhart ME and Allon $\mathrm{M}$. Clinically immature arteriovenous hemodialysis fistulas: effect of US on salvage. Radiology. 2008; 246: 299-305.

26. Schmidli J, Widmer MK, Basile C, de Donato G, Gallieni M, Gibbons CP, et al. Editor's Choice Vascular Access: 2018 Clinical Practice Guidelines of the European Society for Vascular Surgery (ESVS). Eur J Vasc Endovasc Surg. 2018; 55: 757-818.

27. Turmel-Rodrigues L, Boutin J-M, Camiade C, Brillet G, Fodil-Chérif M and Mouton A. Percutaneous dilation of the radial artery in nonmaturing autogenous radial-cephalic fistulas for haemodialysis. Nephrology Dialysis Transplantation. 2009; 24: 3782-8.

28. Long B, Brichart N, Lermusiaux P, Turmel-Rodrigues L, Artru B, Boutin JM, et al. Management of perianastomotic stenosis of direct wrist autogenous radial-cephalic arteriovenous accesses for dialysis. J Vasc Surg. 2011; 53: 108-14.

29. Turmel-Rodrigues L, Mouton A, Birmelé B, Billaux L, Ammar N, Grézard O, et al. Salvage of immature forearm fistulas for haemodialysis by interventional radiology. Nephrol Dial Transplant. 2001; 16: 2365-71.

30. Ahmed $\mathrm{O}$, Patel M, Ginsburg M, Jilani D and Funaki B. Effectiveness of collateral vein embolization for salvage of immature native arteriovenous fistulas. Journal of Vascular and Interventional Radiology. 2014; 25: 1890-4.

31. Lee T, Ullah A, Allon M, Succop P, El-Khatib M, Munda R, et al. Decreased cumulative access survival in arteriovenous fistulas requiring interventions to promote maturation. Clin J Am Soc Nephrol. 2011; 6: 575-81.

32. Harms JC, Rangarajan S, Young CJ, Barker-Finkel J and Allon M. Outcomes of arteriovenous fistulas and grafts with or without intervention before successful use. J Vasc Surg. 2016; 64: 155-62

33. Ravani P, Quinn RR, Oliver MJ, Karsanji DJ, James MT, MacRae JM, et al. Pre-emptive correction for haemodialysis arteriovenous access stenosis. Cochrane Database Syst Rev. 2016; 2016: Cd010709.

34. Aragoncillo I, Abad S, Caldés S, Amézquita Y, Vega A, Cirugeda A, et al. Adding access blood flow surveillance reduces thrombosis and improves arteriovenous fistula patency: a randomized controlled trial. J Vasc Access. 2017; 18: 352-8.

35. Aragoncillo I, Amézquita Y, Caldés S, Abad S, Vega A, Cirugeda A, et al. The impact of access blood flow surveillance on reduction of thrombosis in native arteriovenous fistula: a randomized clinical trial. J Vasc Access. 2016; 17: 13-9.

36. Hwang SD, Lee JH, Lee SW, Kim JK, Kim M-J and Song JH. Comparison of ultrasound scan blood flow measurement versus other forms of surveillance in the thrombosis rate of hemodialysis access: A systemic review and meta-analysis. Medicine. 2018; 97: e11194-e.

37. Allon M and Robbin ML. Increasing arteriovenous fistulas in hemodialysis patients: Problems and solutions. Kidney Int. 2002; 62: 1109-24.

38. Aragoncillo Sauco I, Ligero Ramos JM, Vega Martínez A, Morales Muñoz Á L, Abad Estébanez S, Macías Carmona N, et al. Vascular access clinic results before and after implementing a multidisciplinary approach adding routine Doppler ultrasound. Nefrologia. 2018; 38: 616-21.

\section{ORCID}

Rui F. Silva iD 0000-0003-4244-2459

Hugo Diniz iD 0000-0002-8476-1338

Miguel Relvas (iD) 0000-0002-2947-1610

José Silvano (iD) 0000-0002-5266-2300

Ana Malheiro iD 0000-0002-0860-4648

Luís Coentrão iD 0000-0003-1124-5073

\section{Correspondence to:}

Rui F. Silva, MD

Serviço de Nefrologia do Centro Hospitalar de São João

Alameda Prof. Hernâni Monteiro, 4200-319 Porto

E-mail: rui.fernando.o.silva@gmail.com 